\title{
Surface modification technique to enhance metallurgical and mechanical properties of alloy C-276 weldment by laser shock peening without coating
}

\author{
S A NITHIN JOSEPH REDDY ${ }^{1,3}$, E THRINADH ${ }^{1}$, S PRABHAKARAN $^{2}$, S KALAINATHAN $^{2}$, \\ $\mathrm{N}_{\text {ARIVAZHAGAN }}{ }^{1}$ and M MANIKANDAN ${ }^{1, *}$ \\ ${ }^{1}$ School of Mechanical Engineering, Vellore Institute of Technology (VIT), Vellore 632014, India \\ ${ }^{2}$ Centre for Crystal Growth, Vellore Institute of Technology (VIT), Vellore 632014, India \\ ${ }^{3}$ Hyundai Motor India Limited, Chennai 602117, India \\ e-mail: mano.manikandan@gmail.com
}

MS received 7 March 2018; revised 1 May 2018; accepted 4 June 2018; published online 30 October 2018

\begin{abstract}
Microsegregation of alloying elements is prone to hot cracking in the weldment of alloy C-276. The formation of topologically close packed phases $\mathrm{P}$ and $\mu$ is largely responsible for the hot cracking. The present study articulates the effect of laser shock peening (LSP) to improve the metallurgical and mechanical properties of the weld joint. The weld joint was fabricated by pulsed current gas tungsten arc welding (PCGTAW) using an ERNiCrMo-3 filler wire. LSP without coating was carried out on the cap surface of the weldment. Microstructural studies were carried out to compare the as-welded and laser-peened microstructure on the fusion zone. The results show that a fine equiaxed dendritic structure was observed in both conditions. EDS analysis was carried out to evaluate the microsegregation of alloying elements. EDS analysis indicates that there are no secondary intermetallic phases. X-ray diffraction analysis was carried out to evaluate the phase change and crystallite size in the as-welded and laser shock peened fusion zone. The result shows $48.99 \%$ reduction in crystallite size after LSP. Hardness and tensile strength results indicate there is a consequential increase in laser shock peened specimen compared with as-welded specimen.
\end{abstract}

Keywords. Pulsed current arc welding; laser shock peening; microsegregation; mechanical properties.

\section{Introduction}

Nickel-based superalloy C-276 is a derivative of $\mathrm{Ni}-\mathrm{Cr}-\mathrm{Mo}$ ternary system. The alloy finds wide range of application in naval and nuclear industries due to its high corrosion resistance $[1,2]$. Welding of this alloy is possible by traditional arc welding techniques such as metal inert gas (MIG) and tungsten inert gas (TIG) welding. The major issue associated with arc welding of alloy C-276 is hot cracking due to microsegregation of alloying elements. Microsegregation of alloying elements is largely responsible for the formation of topologically close packed phases (TCP) like $\mathrm{P}$ and $\mu$ at the end of the solidification. These phases reduce the metallurgical, mechanical and corrosion properties of the weld joint [3]. Cieslak et al [4] investigated the effect of welding on metallurgy of different grades of Ni-Cr-Mo-based super-alloys C-4, C-22 and C-276. Segregation of alloying elements Mo and W leads to the formation of TCP phases such as $\mathrm{P}$ and $\mu$ in the alloy C-276 during gas tungsten arc welding.

*For correspondence
Manikandan et al $[5,6]$ examined the microstructure and tensile properties of alloy C-276 fabricated by GTA and PCGTA welding techniques. Specimens welded by PCGTA technique show reduced microsegregation with improved mechanical properties compared with GTAW. Suitable selection of welding process and parameters alleviates the effect of microsegregation of alloying elements. Manikandan et al [5, 6] and Ma et al [7] reported that welding of alloy C-276 by high-density welding process shows reduced microsegregation as compared with the arc welding techniques. Ahmad et al [8] also reported that the electron beam welded alloy C-276 did not show the presence of microsegregation in the fusion zone due to rapid solidification. Arulmurugan and Manikandan [9] investigated the metallurgical and mechanical properties of alloy 686 by GTAW and PCGTAW techniques. Weld joints fabricated by PCGTAW reveal fine microstructure with the absence of Mo-rich secondary phases in weld zone and yield significantly better mechanical properties compared with GTAW. The authors reported that lower heat input and faster cooling rate are directly responsible for enhancement of weldment properties. 
Table 1. Chemical composition of base metal and filler wire.

\begin{tabular}{lcccccccccc}
\hline & \multicolumn{1}{c}{} & \multicolumn{1}{c}{ Chemical composition (wt\%) } \\
\cline { 2 - 11 } Base metal/filler wire & Ni & Mo & Cr & W & Co & Mn & Fe & Nb & Others \\
\hline Alloy C-276 & Bal. & 16.36 & 15.83 & 3.45 & 0.05 & 0.41 & 6.06 & - & $0.17(\mathrm{~V}), 0.005(\mathrm{P}), 0.002(\mathrm{~S}), 0.02(\mathrm{Si}), 0.005(\mathrm{C})$ \\
ERNiCrMo-3 & Bal. & 10.0 & 22.0 & - & - & 0.5 & 1.0 & 4.5 & $0.015(\mathrm{P}), 0.015(\mathrm{~S}), 0.5(\mathrm{Si})$ \\
& & & & & & & & & $0.5(\mathrm{Cu}), 0.4(\mathrm{Al}), 0.4(\mathrm{Ti}), 0.1(\mathrm{C})$ \\
\hline
\end{tabular}

Table 2. PCGTA welding process parameters.

\begin{tabular}{lcccccc}
\hline $\begin{array}{l}\text { Peak } \\
\text { current (A) }\end{array}$ & $\begin{array}{c}\text { Background } \\
\text { current (A) }\end{array}$ & $\begin{array}{c}\text { Pulse frequency } \\
(\mathrm{Hz})\end{array}$ & $\begin{array}{c}\text { Pulse-on time } \\
(\%)\end{array}$ & $\begin{array}{c}\text { Voltage } \\
(\mathrm{V})\end{array}$ & $\begin{array}{c}\text { Shielding } \\
\text { gas }\end{array}$ & $\begin{array}{c}\text { Flow rate } \\
(\mathrm{l} / \mathrm{min})\end{array}$ \\
\hline 213 & 145 & 6 & 50 & 13 & Argon & 15 \\
\hline
\end{tabular}

In laser shock peening (LSP), a state-of-art surface and subsurface modification technique, shock waves imparting plastic deformation of material are produced. Residual stresses developed are compressive in nature, enhancing metallurgical and mechanical properties of material to a great extent as reported by Devendranath Ramkumar et al [10]. During peening, fragmentation of larger grains and development of twinning matrix result in formation of sub-grain boundaries. On further exposure, the sub-grains disintegrate into fine equiaxed grains as reported by Chen et al [11].

Devendranath Ramkumar et al [10] investigated the effect of laser peening on the tensile strength and impact toughness of dissimilar weldments. The authors observed that the tensile strength and hardness of weld joint improved significantly with a scant reduction of toughness after LSP. Chen et al [11] reported that the LSP results in grain refinement and transformation of deleterious tensile stress to beneficial compressive stress. The authors observed improvement in hardness and fatigue properties of weldments after LSP. Chandrasekar et al [12] studied the influence of LSP on alloy 600 produced by activated flux tungsten inert gas (ATIG) welding. The authors reported that the refined microstructure and compressive residual stress increase strength of the weld joint compared with the as-welded condition.

It is evident from the published literature that no work has been reported on LSP of weldments with particular reference to the extent of microsegregation of alloying elements in the alloy $\mathrm{C}-276$. The aim of present study is to bridge this knowledge gap by reducing microsegregation of alloying elements in the fusion zone, thereby avoiding the formation of deleterious phases.

\section{Experimental procedure}

\subsection{Material and welding procedure}

Base metal alloy C-276 was purchased in the form of hotrolled and solution-annealed plates. The chemical compositions of the base metal and filler wire employed are listed in table 1. The base material was machined to $130 \mathrm{~mm} \times 55 \mathrm{~mm} \times 4 \mathrm{~mm}$ dimension using a wire cut electrical discharge machine (EDM) to perform weld trials. Before welding, the plates were cleaned with acetone to remove oil, dust and other contaminants. Butt joint configurations (V-groove with $60^{\circ}$ and root gap of $1 \mathrm{~mm}$ ) are employed for arc welding with an ERNiCrMo-3 filler wire of $1.6 \mathrm{~mm}$ diameter. Table 2 shows the process parameters employed in the current study. Specially designed fixture with a copper back plate was employed to prevent distortion and for efficient dissipation of heat during welding.

\section{$2.2 L S P$}

LSP without coating (LSPwC) was done on the surface of the weldment. A Q-switched Nd:YAG laser (LPY704G-10, Litron Lasers Ltd) source of $350 \mathrm{~mJ}$, pulse duration of $10 \mathrm{~ns}$ and wavelength of $1064 \mathrm{~nm}$ with laser spot overlapping of $70 \%$ was employed to perform peening. Prior to LSP, the weldment was cleaned with acetone to remove contaminants from the surface. The layout of machine set-up in the present study used for peening process is shown in figure 1 . Laser beam from the source reaches the material surface through a dichromatic mirror kept at $45^{\circ}$ and biconvex lens. An electric dryer is placed near the biconvex lens to protect from water spilling during LSP process. Coupons were kept on a computer-controlled holder to govern movement along $X-Y$ axes. No sacrificial layer was used during the process. Coupons were kept under a stream of water, acting as a containment layer, to remove ablated material from specimen surface. Thickness of containment layer was maintained at 1-2 $\mathrm{mm}$ throughout the process.

\subsection{Metallurgical characterization}

As-welded and laser shock peened coupons were extracted for metallurgical and mechanical characterization; the coupons were cut perpendicular along the weld direction. 


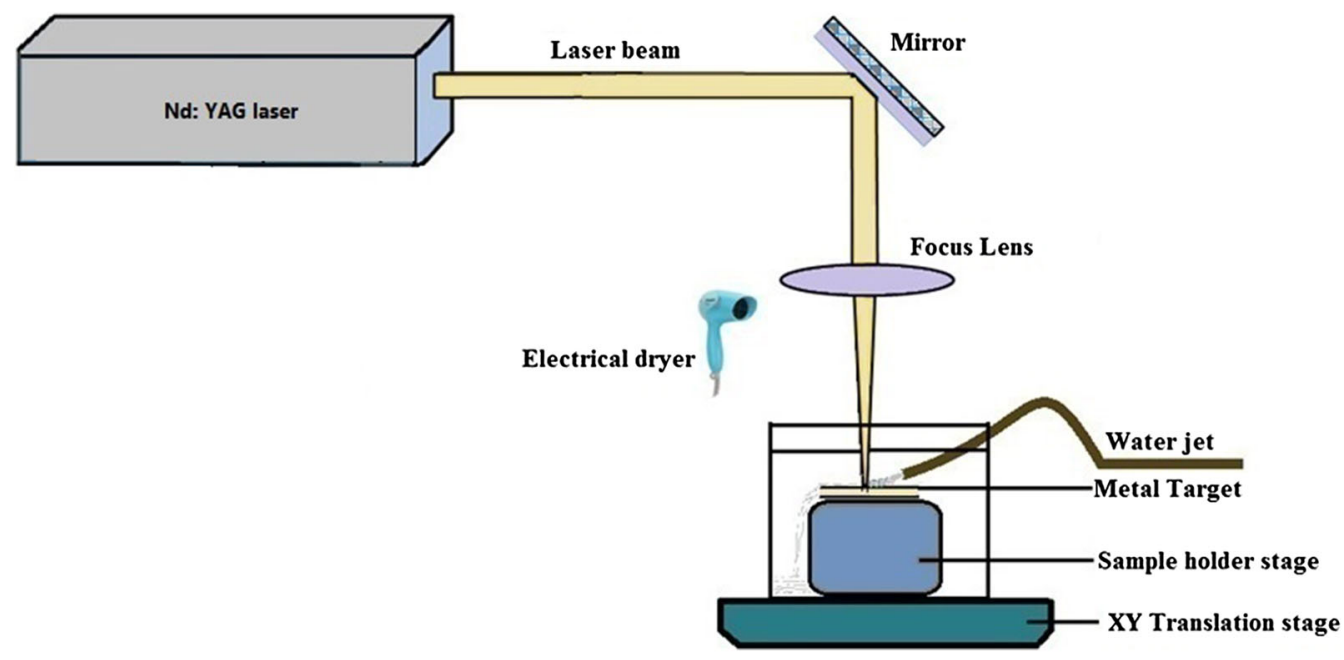

Figure 1. Schematic view of laser shock peening.

Microstructure specimens were then manually polished using 220-2000 grid SiC papers followed by $0.5 \mu \mathrm{m}$ alumina powder polishing in velvet cloth. Finally, water polishing was done to obtain the mirror-like finish. To examine the microstructure, the etchant prepared was a mixture of $80 \mathrm{ml} \mathrm{HCL}, 4 \mathrm{ml} \mathrm{HNO}_{3}, 1 \mathrm{~g} \mathrm{CuCl}_{2}$ and $20 \mathrm{ml}$ glycerol. Microstructural analysis was carried out using optical and scanning electron microscopes. EDAX analysis was carried out to evaluate the extent of microsegregation in the subsurface regions of fusion zone. An X-ray diffractometer (Bruker D8) with a $\mathrm{Cu}_{\mathrm{k} \alpha}$ radiation source having a wavelength of $1.54 \AA$ was used to analyse the phases and to calculate the crystallite size in the as-welded and laser shock peened fusion zones.

\subsection{Mechanical characterization}

Surface roughness of laser shock peened specimen was measured using a surface profilometer (Mahr surf GD 120) with diamond tip stylus of $2 \mathrm{~mm}$ diameter on the base metal and fusion zone. Tensile specimens were prepared in conformance to ASTM E8 standard to assess the strength and ductility of weld joints. Testing was done in triplicate to ensure reproducibility using an universal testing machine (Instron, 8801) at a strain rate of $2 \mathrm{~mm} / \mathrm{min}$. Vickers's microhardness (Matsuzawa) with a standard load of $500 \mathrm{gf}$ for a dwell time of $10 \mathrm{~s}$ at a regular interval of $0.25 \mathrm{~mm}$ was used to evaluate the hardness variation along the traverse plane of weldment.

\section{Results and discussion}

\subsection{Microstructural examination}

Figure 2 shows the fusion zone microstructure of alloy C-276 as-welded and LSP welded. Fine equiaxed dendritic structures can be observed from the micrograph of both fusion zones. The higher cooling rate achieved in
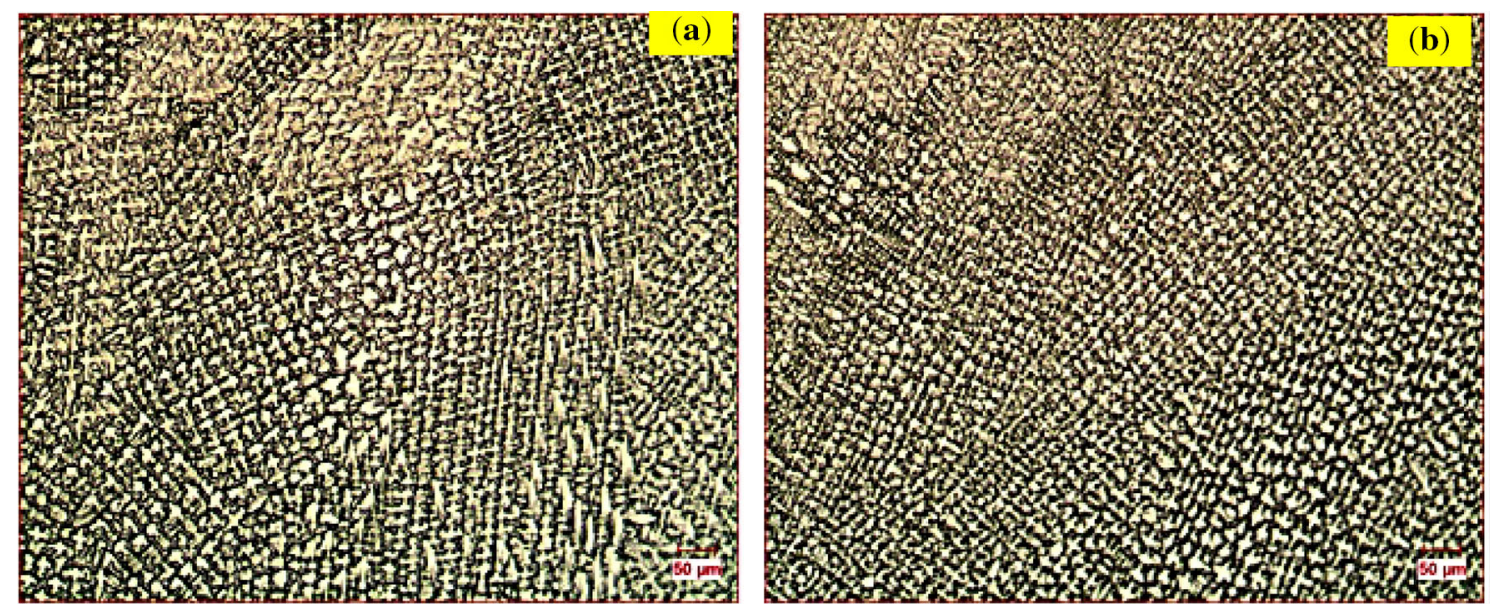

Figure 2. Fusion zone microstructure of (a) as-welded and (b) laser shock peened specimens. 
PCGTAW is largely responsible for the observed fine equiaxed structure; cooling rate determines rate of growth of liquid-solid interface movement. Equilibrium temperature gradient in this region significantly differs from those in other regions in the sample due to compositional variation and enrichment of alloying elements. It depends on rate of enrichment and rate of alloying element diffusing into liquid metal. In a high cooling rate condition, due to constitutional super-cooling, the value of equilibrium temperature gradient is greater than actual temperature gradient, which results in the formation of fine equiaxed grains [13]. The crystallite size refinement was higher in laser shock peened as compared with as welded. During the LSP, the fusion zone undergoes severe plastic deformation; it leads to disintegration of the grains in as-welded condition to sub grains in laser-peened condition [14, 15].

\subsection{SEM/EDS analysis}

Figure 3 shows the SEM/EDS analysis at weld centre and in interface regions of laser shock peened specimen. Emphasis was focused on the elements $\mathrm{Ni}, \mathrm{Cr}, \mathrm{Mo}, \mathrm{W}$ and $\mathrm{Fe}$ as they are directly responsible for formation of deleterious intermetallic phases of $\mathrm{P}$ and $\mu$ at the end of solidification. Figure $3 \mathrm{a}$ and $\mathrm{b}$ shows the high-
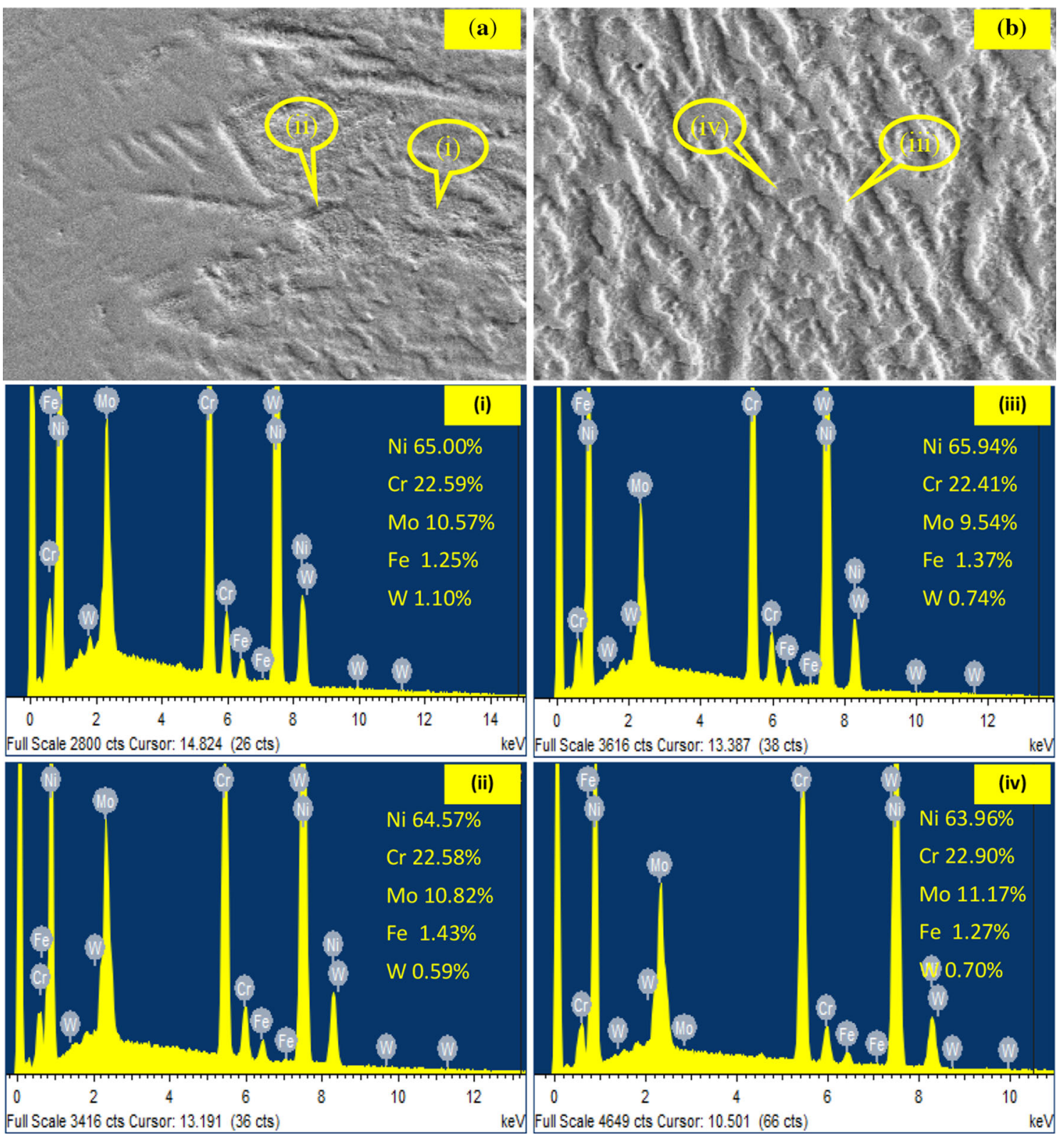

Figure 3. SEM/EDS analysis of laser shock peened welded alloy C-276. (a) SEM weld interface and (b) SEM weld centre: (i) weld interface interdendritic zone, (ii) weld interface dendritic core, (iii) weld centre interdendritic zone and (iv) weld centre dendritic core. 
magnification SEM image of laser shock peened fusion zone. It is observed from the microstructure that there is no evidence for the precipitation of intermetallic phases at the weld centre and in weld interface regions. EDS analysis was carried out on the matrix and interdendritic zones of weld centre and weld interface region.

Figure 3 (i and ii) presents the EDS point analysis of weld interface matrix and interdendritic regions. Figure 3 (iii and iv) presents the corresponding regions of weld centre. It is observed from the EDS analysis that both weld centre and interface regions of alloying elements are close to each other. There is no evidence for the segregation of alloying elements. The material subjected to rapid solidification produces fine microstructure, less microsegregation and better solid solubility, which aid in the formation of meta-stable phases $[16,17]$. Rapid solidification by pulsed current gas tungsten arc welding (PCGTAW) decreases the equilibrium diffusion of elements [7, 9]. In addition to PCGTAW, LSP also alleviates the extent of microsegregation in surface and sub-surface regions of the substrate. During LSP, specimens are submerged in a stream of water, which acts as a cooling medium and reduces the temperature, yielding rapid solidification. Results from EDS analysis indicate that microsegregation has been completely suppressed in comparison with previous studies reported by Manikandan et al [5, 6].

\subsection{XRD analysis}

XRD analysis of as-welded and laser shock peened specimens are shown in figure 4. It is observed from the XRD analysis the peaks are shifted towards lower angle in the laser shock peened specimen. This indicates the strain induced in crystal lattice of laser shock peened specimen. Peaks of high intensity levels indicate residual stresses, which cause misorientation of the structure. The presence of Ni peaks (111) (200) (220) and (311) after LSP indicates

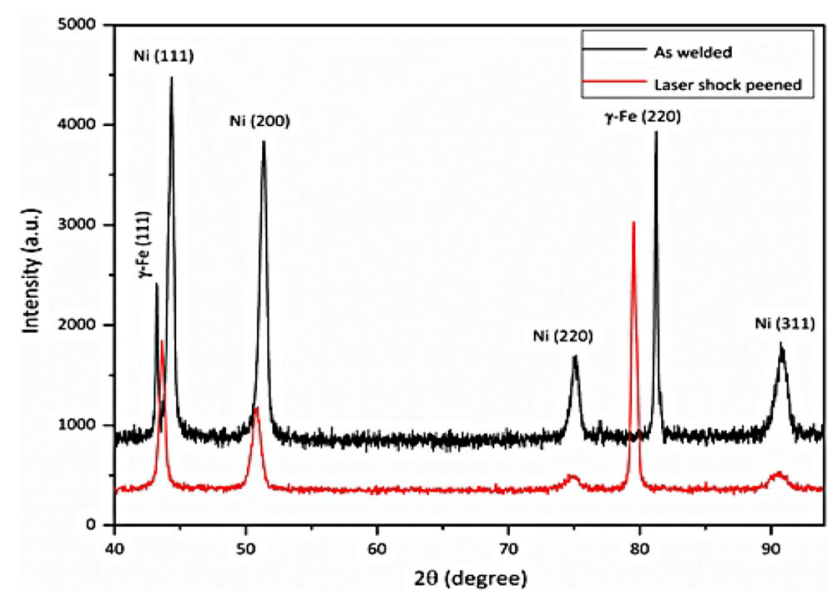

Figure 4. XRD analysis of as-welded and laser shock peened specimens.
Table 3. Values of grain size $(D)$, dislocation density $(\delta)$ and microstrain $(\varepsilon)$ of weldments.

\begin{tabular}{lcc}
\hline Parameter & As welded & Laser shock peened \\
\hline Crystallite size $(D)$ & $6.47537 \times 10^{-9}$ & $3.30262 \times 10^{-9}$ \\
Dislocation density $(\delta)$ & $2.38490 \times 10^{16}$ & $9.16817 \times 10^{16}$ \\
Microstrain $(\varepsilon)$ & $2.23365 \times 10^{-03}$ & $2.87785 \times 10^{-03}$ \\
\hline
\end{tabular}

retention of austenite. It is evident from peak broadening of (200) (220) and (311) that LSP results in decrement of crystallite size. The crystallite size $(D)$, dislocation density $(\delta)$ and microstrain $(\varepsilon)$ induced in the grain of crystalline material can be calculated quantitatively by the formulas given here [18]. Values of crystallite size, dislocation density and microstrain of as-welded and laser shock peened weldment are given in table 3 .

$$
\begin{gathered}
D=\frac{0.94 \lambda}{\beta \cos \theta}(\mathrm{m}) \\
\delta=\frac{1}{D^{2}}\left(\text { lines } / \mathrm{m}^{2}\right) \\
\varepsilon=\frac{\beta \cos \theta}{4}\left(\text { lines }^{-2} / \mathrm{m}^{-4}\right)
\end{gathered}
$$

$\lambda$ is the wavelength of $X$-ray used $\left(1.54 \times 10^{-10} \mathrm{~m}\right), \beta$ is the broadening of diffraction line by full-width half-mean method (FWHM) in radians and $\theta$ is the angle of diffraction in radians. The average crystallite size is reduced by $3.17275 \times 10^{-9} \mathrm{~m}$, producing a refinement of $48.99 \%$. The high strain rate induced by laser shock waves generates most of the slips in grain and increases the dislocation density $[14,15]$. Broadening of diffraction peaks is an indication of strain or microstrain induced in the material $[19,20]$.

\section{Mechanical characterization}

\subsection{Effect of LSP on mechanical properties}

Table 4 compares the mechanical properties of as-welded and laser shock peened specimens. The surface roughness values of base metal and laser shock peened fusion zone

Table 4. Mechanical properties of the samples.

\begin{tabular}{lcc}
\hline Characterization & As welded & Laser shock peened \\
\hline Tensile strength (MPa) & 706.00 & 756.33 \\
Average micro-hardness (HV) & \\
$\quad$ Fusion zone & 239.40 & 331.85 \\
Heat-affected zone & 221.90 & 320.90 \\
Base metal & 212.40 & 316.35 \\
Surface roughness & - & 2.40 \\
$\quad(\mu \mathrm{m})$ (fusion zone) & & 53 \\
Elongation percentage & 29.75 & 5 \\
\hline
\end{tabular}




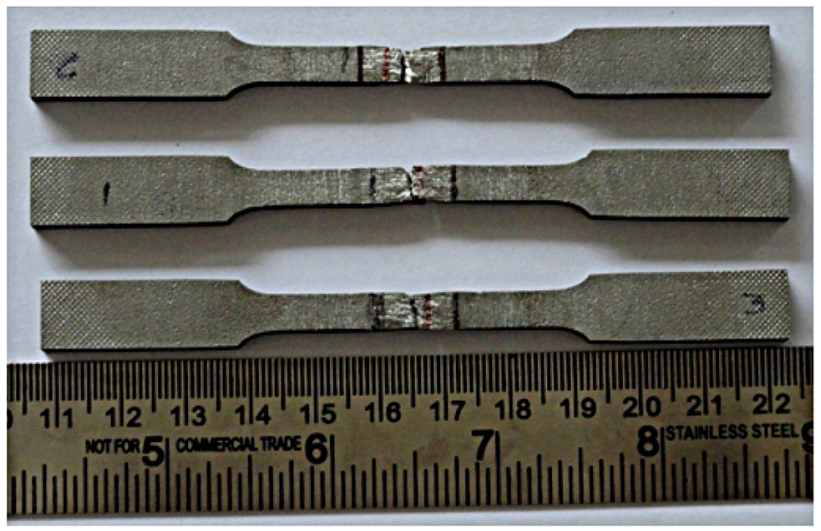

Figure 5. Tensile fractured laser shock peened specimen.

are, respectively, 1.76 and $2.40 \mu \mathrm{m}$. It is inferred from the results that roughness increases gradually from base metal to laser shock peened fusion zone. Absence of ablative layer (without coating) increases surface roughness due to direct laser ablation on the metal surface [21, 22]. Fine microstructure and absence of intermetallic phases enhance the strength and ductility of weld joints. Evidently, percentage of elongation has been increased by $23.25 \%$ compared with as-welded coupon. Figure 5 shows a photograph of laser shock peened tensile specimens. It is understood from the figure that fracture occurred in the fusion zone. The average tensile strength of laser shock peened weld joint is $756.33 \mathrm{MPa}$. The tensile strength of as-welded joint reported by the authors in their previous study was 706 MPa. Detrimental tensile residual stresses emanating during solidification in as-welded specimen deteriorate the mechanical properties of weldment, leading to early failure of weldment in service. After LSP the strength of weld joint increases by $7.13 \%$.

Figure 6 shows the fractured surface micrograph for understanding the mode of failure in laser shock peened weldment. Presence of white tearing ridges, and merging of voids (micro and macro) and dimples indicate that ductile mode of fracture has taken place. The mode of fracture is also in good concurrence with the increase in elongation percentage as shown in table 4. Similar observations were also reported by Chandrasekar et al [12]. Figure 7 shows the micro-hardness values of base metal, heat-affected zone and fusion zone of as-welded and laser shock peened weldment. Average hardness was increased by $34 \%$ after LSP. LSP transmutes the tensile to compressive residual stress and increase in dislocation density, improving the mechanical properties of specimen [11, 12].

\section{Correlation of microstructure grain refinement and strengthening mechanism}

It is articulated from the current study that the effect of LSP on alloy C-276 is to significantly improve the mechanical properties of weldment. Micrographs of both the specimens indicate fine equiaxed dendrite structure and absence of microsegregation of alloying elements. The plasma created at the material surface induces shock waves in the material. These shock waves produce plastic deformation and compressive residual stresses on the material surface. Extent of metallurgical changes induced to the depth of material depends on the plasma pressure, which is controlled by the parameters employed. Coarser grains observed at the as-welded

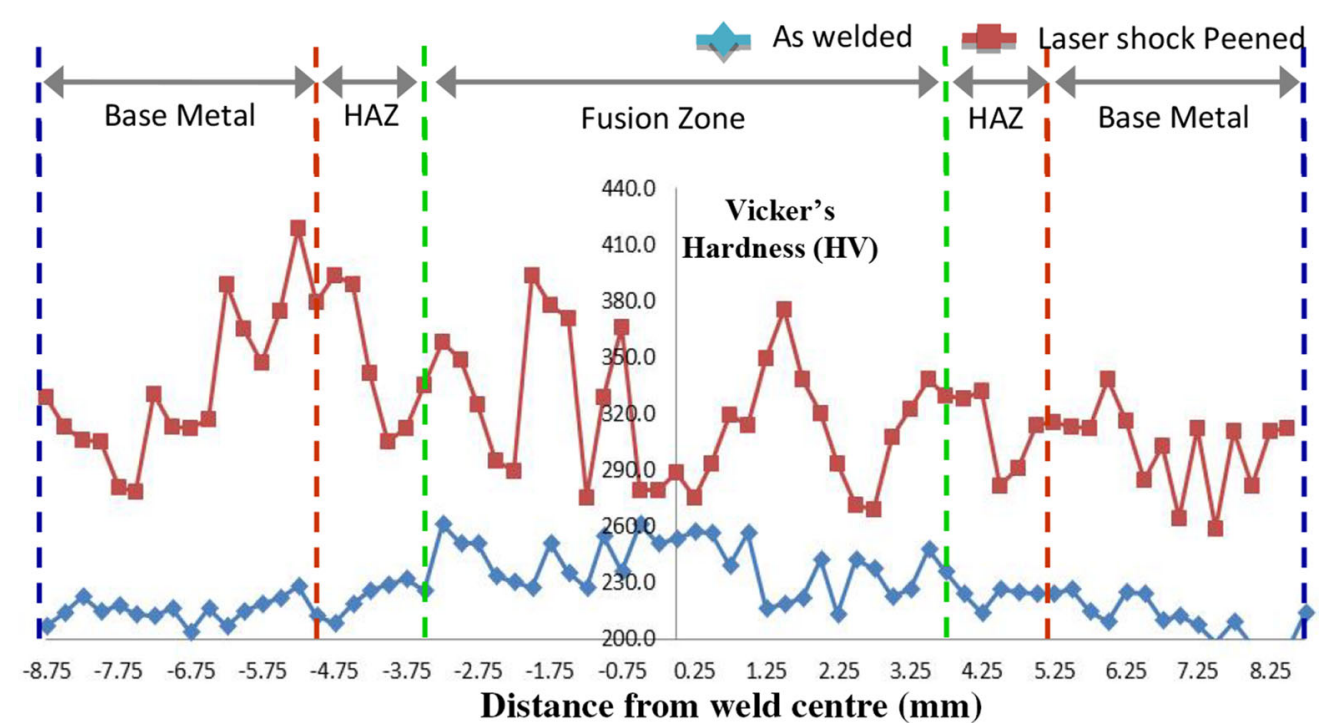

Figure 6. Microhardness of as-welded and laser shock peened specimens. 


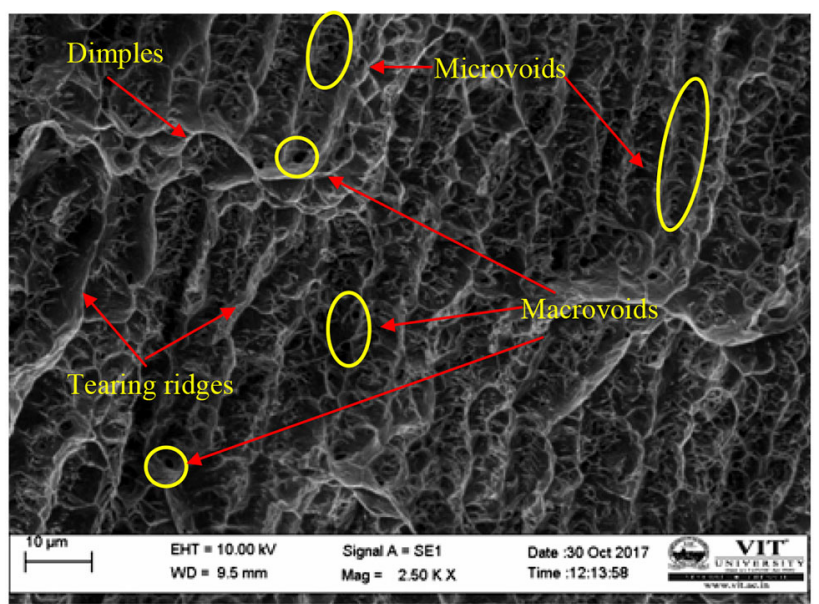

Figure 7. Fractograph of laser shock peened specimen.

microstructure are broken down to sub-grains at the surface and sub-surface regions of laser shock peened condition. Grain size plays a vital role in improving the strength and properties of weldment. As per the Hall Petch equation, grain size is inversely proportional to the hardness value. Increase in hardness also improves the tensile strength of weldment. Compressive residual stress induced also has a significant effect. It is well known that tensile residual stress developed in the fusion welding process degrades the weldment properties. LSP transmutes deleterious tensile residual stress into beneficial compressive residual stresses, improving the weldment properties. From the present research work, it is concluded that LSP improves the strength and hardness of the weld joint.

\section{Conclusions}

The salient features of the research work are listed below

1. Deleterious intermetallic secondary phases were not observed due to rapid solidification by PCGTAW technique.

2. Fine equiaxed microstructure was observed in both the conditions. Laser shock peened weld joint indicate $48.99 \%$ crystallite size reduction compared with aswelded condition

3. Laser shock induced grain refinement and compressive residual stresses, increasing strength of weld joints.

\section{Acknowledgements}

This research did not receive any specific grant from funding agencies in the public, commercial or not-for-profit sectors.

\section{Nomenclature}

$\begin{array}{ll}\lambda & \text { wavelength of X-ray (m) } \\ \beta & \begin{array}{l}\text { broadening of diffraction line by full-width } \\ \text { half-mean method (FWHM) in radians } \\ \text { angle of diffraction in radians }\end{array} \\ \theta & \begin{array}{l}\text { crystallite size (m) } \\ D\end{array} \\ \delta & \text { dislocation density (lines } / \mathrm{m}^{2} \text { ) } \\ \varepsilon & \left.\text { microstrain induced (lines } \mathrm{s}^{-2} / \mathrm{m}^{-4}\right) \\ \text { LSP } & \text { laser shock peening } \\ \text { GTAW } & \text { gas tungsten arc welding } \\ \text { PCGTAW } & \text { pulsed current gas tungsten arc welding }\end{array}$

\section{References}

[1] Hashim M, Sarath Raghavendra K.E, Babu, Muthukannan D and Harshad N 2013 Improvement of wear resistance of Hastelloy C-276 through laser surface melting. Mater. Des. 46: $546-551$

[2] Special Metals Corporation 2013 Inconel alloy C-276 technical data sheet. http://www.specialmetals.com/documents/ Inconel\%20alloy\%20C-276.pdf

[3] Crum J R, Shoemaker L E and Kiser S D 2014 Special alloys and overmatching welding products solve FGD corrosion problems. Special metals welding products, Technical Paper, http://216.71.103.52/documents/Special\%20Alloys\% 20 and $\% 20$ Overmatched $\% 20$ Welding $\% 20$ Products $\%$ 20Solve\%20FGD\%20Corrosion\%20Problems.pdf

[4] Cieslak M J, Headley T J and Romig A D 1986 The welding metallurgy of Hastelloy alloys C4, C22, and C-276. Metall. Mater. Trans. A 17(11): 2035-2047

[5] Manikandan M, Arivazhagan N, Nageswara Rao M and Reddy G M 2014 Microstructure and mechanical properties of alloy C-276 weldments fabricated by continuous and pulsed current gas tungsten arc welding techniques. J. Manuf. Process. 16: 563-572

[6] Manikandan M, Arivazhagan N, Nageswara Rao M and Madhusudhan Reddy G 2014 Improvement of microstructure and mechanical behavior of gas tungsten arc weldments of alloy C-276 by current pulsing. Acta Metall. 28(2): 208-215

[7] Guangyi M A, Dongjiang W U and Dongming G 2011 Segregation characteristics of pulsed laser butt welding of Hastelloy C-276. Metall. Mater. Trans. A 42: 3853-3857

[8] Ahmad M, Akhter J I, Akhtar M, Iqbal M, Ahmed E and Choudhry M 2005 Microstructure and hardness studies of the electron beam welded zone of Hastelloy C-276. J. Alloys Compd. 390: 88-93

[9] Arulmurugan B and Manikandan M 2017 Development of welding technology for improving the metallurgical and mechanical properties of 21 st century Nickel based superalloy 686. Mater. Sci. Eng. A 691: 126-140

[10] Devendranath Ramkumar K, Siva Goutham Kumar P, Radha Krishna V, Chandrasekar A, Dev S, Abraham W S, Prabaharan S, Kalainathan S and Sridhar R 2016 Influence of laser peening on the tensile strength and impact toughness welds of Inconel 625 and UNS S32205. Mater. Sci. Eng. A 676: 88-99 
[11] Chen X, Wang J, Fang Y, Madigan B, Xu G and Zhou J 2014 Investigation of microstructures and residual stresses in laser peened Incoloy $800 \mathrm{H}$ weldments Opt. Laser Technol. 57: 159-164

[12] Chandrasekar G, Kailasanathan C and Verma D K 2017 Investigation on un-peened and laser shock peened weldment of Inconel 600 fabricated by ATIG welding process. Mater. Sci. Eng. A 690: 405-417

[13] Kou S 2003 Welding metallurgy, 2nd ed. Hoboken, New Jersey: John Wiley \& Sons, Inc., pp. 145-209

[14] Lu J Z, Luo K Y, Zhang Y K, Sun G F, Gu Y Y, Zhou J Z and Ren X D 2010 Grain refinement mechanism of multiple laser shock processing impacts on ANSI 304 stainless steel. Acta Metall. 58(16): 5354-5362

[15] Lu J Z, Luo K Y, Zhang Y K, Cui C Y, Sun G F, Zhou J Z, Zhang L, You J, Chen K M and Zhong J W 2010 Grain refinement of LY2 aluminum alloy induced by ultra-high plastic strain during multiple laser shock processing impacts. Acta Metall. 58(11): 3984-3994

[16] Munitz A 1985 Microstructure of rapidly solidified lasermolten Al-4.5 wt\% Cu surfaces. Metall. Trans. B 16: 149-161

[17] Zimmermann M, Carrard M and Kurz W 1989 Rapid solidification of $\mathrm{Al}-\mathrm{Cu}$ eutectic alloy by laser re-melting. Acta Metall. 37(12): 3305-3313
[18] Kishorkumar Khot V, Sawanta Mali S, Nita Pawar B, Rohini Kharade R, Rahul Mane M, Vijay Kondalkar V, Pallavi Patil B, Pramod Patil S, Chang Hong K, Jin Kim H, Heoe J and Popatrao Bhosale N 2014 Development of nanocoral-like $\mathrm{Cd}(\mathrm{SSe})$ thin films using an arrested precipitation technique and their application. New J. Chem. 38: 5964-5974

[19] Pelleg J and Elish E 2002 Stress changes in chemical vapor deposition tungsten silicide (polycide) film measured by X-ray diffraction. J. Vac. Sci. Technol. A 20: 754-761

[20] Reddy J, Kokila M K, Nagabhushan H, Chakradhar R P S, Shivakumar C, Rao J L and Nagabhushan B M 2011 Structural, optical and EPR studies on $\mathrm{ZnO}: \mathrm{Cu}$ nanopowders prepared via low temperature solution combustion synthesis. J. Alloys Compd. 509: 5349-5355

[21] Prabhakaran S and Kalainathan S 2016 Warm laser shock peening without coating induced phase transformations and pinning effect on fatigue life of low-alloy steel. Mater. Des. 107: 98-107

[22] Prabhakaran S and Kalainathan S 2016 Compound technology of manufacturing and multiple laser peening on microstructure and fatigue life of dual-phase spring steel. Mater. Sci. Eng. A 674: 634-645 